\title{
A neighbourhood renewal project in Dalston, Hackney: Towards a new form of partnership for inner city regeneration
}

Received (in revised form): 8 September 2003

\section{Adam Hart}

first lived in Hackney in 1969 and has been a resident parent there since 1990. He is executive director of Hackney Cooperative Developments (HCD). Before joining HCD in 1992 he worked principally in the construction industry, as a social researcher at the Tavistock Institute of Human Relations and the Medical Research Council, for the Northants Probation Department and in a number of seminal enterprises in the arts in London.

\begin{abstract}
This paper revisits a speech given at a conference in July 2002 which presented some prospects for real regeneration, rather than the familiar pattern of gentrification, in the Bradbury Street area of Dalston, Hackney. Since then many of the ideas posited some new, some old - have found support in a wider arena and are now being tested in action across the UK, as the agenda for community-led regeneration and social enterprise gains momentum. The speech ended with the crucial caveat that it was most unlikely that the full beneficial effects on the mainstream economy of such initiatives could be achieved unless appropriate local, regional and national strategies in the public sector could uphold the key principles and rules underlying this approach. This paper retraces these arguments, notes some progress on this front and focuses on the role of the private sector and retail and leisure vitality. A key theme is that the private sector, if it comes to appreciate some pressing realities and adopts these strategic principles, can contribute to real inner-city regeneration. Such regeneration will engage and benefit rather than displace inhabitants. It is suggested that this reflects wider and increasing imperatives for the mainstream economy to become more socially involved at the heart of its business.
\end{abstract}

\section{Keywords:}

regeneration, neighbourhood, renewal, Dalston, Gillett, PVP, social economy, cooperation, devolution, democracy 


\section{Description of Dalston now}

\section{Current regeneration plans: A trigger for real regeneration}

a negative picture, based around its piles of rubbish, poverty, crime, drug dealers, prostitution, street people, vagrants, squatters and alcoholics. But in its totality the real picture, and Dalston's possible future, is very different.

Here one can find nearly every kind of food in the shops, restaurants and takeaways: Indian, Italian, Bangladeshi, Pakistani, Russian, Anatolian, Turkish, Kurdish, Greek, African, Caribbean, Asian and Chinese. On the weekends the restaurants are usually full. Dalston is the UK home of reggae and hip-hop and reputedly has more nightclubs than the West End and more artists than anywhere else in London. It is also home to the Rio Cinema and the Arcola Street Theatre, which together provide a rich variety of mainstream and art-house productions, Centerprise and Stoke Newington bookshops, the Dalston Jazz Cafe, the Vortex Jazz Café, galleries, managed workspaces, churches, mosques, temples, community associations and so on.

Retail vitality in Dalston has been sustained for many years by the huge Ridley Road market where cheap and varied goods (some infamous, some just fascinating) are sold, especially food but many other items as well. Such attractions account for the many thousands of people who pour into this area every day of the week.

Across the High Street from Ridley Road is the Bradbury Street area, which was first brought back into use from almost complete dereliction by Hackney Cooperative Developments (HCD) and the London Borough of Hackney (LBH) in 1982. Until recently this particular area has been marginal to the Ridley Road epicentre, apart from providing car-parking and some early market leads such as wholefoods, complementary medicines and bicycle-repair services - which have now entered the mainstream in the High Street and Dalston Cross shopping centre, or have migrated to Islington and beyond.

Since 1996, through HCD's work with architects Hawkins/Brown and $\mathrm{LBH}$, a sense of place has started to emerge in this area, based upon the rehabilitated managed workspace offices and workshops with their first- and second-storey balconies above new market trading units. Besides the successful Jazz Café, among these units are local entrepreneurs including retailers in music, jewellery, crafts and beauty products, plus hair salons, a tailor, an African bookshop, designer-makers, craftspeople, graphic artists, architects, media and IT workers and arts and voluntary sector groups. There is a high level of sustainable black, ethnic minority and female entrepreneurs and community groups. Many of these were assisted through start-up grants, advice from HCD and other agencies on how to move to market sustainability, specialist services, low-cost loans and the availability of affordable workspace.

These economic and spatial developments have prefigured the proposed conversion of the car-park to a town-centre square (Gillett Square) as a meeting place and as a landmark arena for local cultural events. Around the square will be the Dalston Culture 


\section{Support from GLA, EC}

\section{Three-sector partnership}

\section{Devolved management}

\section{Jane Jacob's recipe for successful neighbourhoods}

House, extensive new housing, offices, shops, workshops and community facilities. These developments will engage with the existing diverse population of shoppers, inhabitants, workers and informal traders in the whole of the Dalston area, and extend to new markets, activities, visitors and inhabitants.

The fact that Dalston has been selected as a focus by Hackney's local strategic partnership, and that it falls within the European Regional Development Fund (ERDF) Objective Two area, bodes well for its immediate future. Moreover, the Gillett Square partnership's plans have been selected as one of ten pilot projects for London by the Greater London Authority's (GLA) Urbanism and Architecture Panel (AAUU), chaired by Lord Rogers. The Gillett Square partnership is a three-sector group comprising the local authority, Groundwork Hackney, developers McDonald Egan and HCD. Other potential partners include New Islington and Hackney Housing Association, the Peabody Trust and the Vortex Jazz Foundation. This is the culmination of many years' exploratory work, in consultation with the local community and with the assistance of a high-quality design team (architects Hawkins/Brown, Stock Woolstencroft, Turkington Whitelaw and others). Through this process a coherent and uplifting vision for the area has emerged which has helped to convince the AAUU that the ground conditions for successful economic, social and spatial development exist on this site in Dalston.

Not only do these plans entail an uplifting physical redevelopment of the area, but the partnership's structure is the foundation for building an innovative, devolved management organisation to secure an enduring future for this site, which will develop and maintain the common long-term interests of all the sectors represented.

This perception is conditioned by an appreciation of Jane Jacob's famous four conditions for successful city neighbourhoods: ${ }^{1}$

- mixed use (housing, retail, office, workshops etc)

- small blocks (intricate layouts, many corners, avoidance of long stretches)

- aged buildings (for aesthetic and economic reasons, allowing significant elements of low rental)

- density (achieving critical mass, community safety).

These conditions allow the space for market trading, cranky bookstores, curiosity shops, specialist delicatessens, owner-run cafés, jazz dives, bespoke tailors, street artists and so on, which still just (and only just) survive in places like Montparnasse, Covent Garden, Notting Hill, Greenwich Village and many other less famous neighbourhoods that are magnets for the public and crucially define the enduring values of civic life (eg vitality, cosmopolitanism, the 'buzz' of a city). All these and much more (affordable homes, affordable workplaces, public space) are essential ingredients for any urban renaissance. 
Civil servants, planners, developers and politicians are now beginning to recognise and accept these conditions rather than move to obliterate them, by intent or default. Voluntary sector organisations like HCD, close to the local knowledge economy and the regeneration agenda, need to be seen as organisations which can better identify and reflect the true value of such enormous potential in conditions as found in Dalston.

Nevertheless, none of the hopeful prospects for this work has much chance of enduring success unless there is a wider strategic context in which the deepening divides between rich and poor, private luxury and public squalor, can be reversed. As far as Hackney and London are concerned, neither the local nor metropolitan authorities have much to offer on this front at the moment. Hackney Council has yet to produce a coherent regeneration strategy or development plan (beyond selling off everything to the private sector, with little to no planning gain), although the new local strategic partnership for neighbourhood renewal might move this on. The London Development Agency's current economic strategy — the London Mayor's draft plan — at present goes no further than affordable housing on the back of the expansion of the city, while dreaming of a public transport revolution.

While no doubt there are many practical considerations which have determined these authorities' shortcomings and constraints, not least imposed by perceptions of central government which regard transfer to the private sector as inherently beneficial, there is a pervasive failure to recognise that successful economic development is a social enterprise, and that in regeneration the social and the economic are inseparable. Nevertheless there are hopeful signs of new thinking in government, as reflected in the Office of the Deputy Prime Minister's (ODPM) white paper Our Towns and Cities $2000^{2}$ and in much of the work of the new Department of Trade and Industry (DTI) Social Enterprise Unit, as well as the government's recent proposals for area action planning, involving all sectors.

There is, however, much further to go on this front; much of this new thinking has yet to percolate through to subsidiary bodies. Unless one comes to grips with this, and all that it implies, one is heading for a crisis far deeper than the housing crisis, as a result of which, with rocketing commercial rents in areas like Dalston, much work and local employment itself becomes unaffordable, and society fails yet further to cohere. For instance, it is necessary to start to think seriously about the concept of affordable workplaces as well as affordable housing.

At root there is a failure to challenge convention, and in particular to face the fact that economic growth per se is of little enduring value if it progressively erodes the environment, promotes inequality and exclusion, creates unhappiness or displaces social functions into the marketplace. As economists and social 
commentators such as J. K. Galbraith, Will Hutton, Joseph Stiglitz, George Monbiot ${ }^{3}$ and many others have intimated, what is needed is a new economic development paradigm which embraces a wider range of considerations than ever.

For instance, the Observer ${ }^{4}$ reports that 'Professor Richard Florida's ideas are revolutionising the thinking of America's civic leaders' who tell readers that 'without diversity, without weirdness, without difference, without tolerance, a city will die' . . . 'Cities don't need shopping malls and convention centres to be economically successful, they need eccentric people who will attract the economically creative people upon whom economic success depends.' These people 'want diversity and an exciting environment, a street-level music scene and a place that is teeming with different kinds of people'. ${ }^{5}$ In May 2003, the Royal Institute of Chartered Surveyors, in association with the think-tank Demos, hosted a highprofile conference which was led by Florida, who debated these ideas with many other academics, writers, professionals and politicians in this field, as well as with the large audience.

It is not difficult to apply Florida's findings to Dalston. They explain why the 1980s' Dalston Cross shopping centre (the conventional suburban mall) failed to drive regeneration in this area, and they provide good grounds for the likely success of the Gillett Square partnership's plans.

Along with other housing (some live/work, some affordable), retail outlets, community and cultural facilities and managed workspace developments in the Dalston area, it is not hard to see a new cultural quarter, catering for a wider band of spending, developing here. With HCD's ownership of the south and west flanks of the square there is a fair ingredient of affordable work and retail space, and the site has both density and many intricacies.

Many other areas have experienced regeneration as a result of the opportunities and creative energies such as currently exist in Dalston, only to see them packaged and eventually degraded by short-term market forces, leading one round a familiar cycle of boom and bust, gentrification and displacement. This has been the pattern of much post-war town-centre redevelopment up and down the country, and can apply in the inner city to places like the Docklands and Hoxton. In general this process has resulted, across the world, in exactly the same corporate chain stores selling the same products, pale imitations and pastiches of the original items. Where these unwelcome changes have been resisted (for example, Covent Garden) one is likely to find a prior history of mobilisation of the local community and a pattern of small-scale land ownership.

This is not to argue against big high-street names coming into Dalston. They are needed, in appropriate measure. Such retail outlets may well represent part of the visible surface, but it would be necessary to look further than their success for evidence of a sustainable neighbourhood and real regeneration. For this outcome 
there needs to be, at the very least, an enduring mix of tenures encompassing a wide range of different business and housing sectors, rather than for any single one to dominate.

\section{PROPOSITIONS FOR ACHIEVING SUSTAINABILITY}

- Successful neighbourhoods will have roots, character, cohesion, stability and relative permanence, independent of the particular individuals in them at any one time.

- At the most down-to-earth level, sustainability means community/cooperative land ownership, but it also means good design, wise and responsible development and intensive management. This means principled, firm and effective organisation and responsive systems.

- This approach goes beyond the current vogue for individual social entrepreneurship and charismatic leadership. Such leaders are only as good as their accountability to the communities they represent and inspire.

- City neighbourhoods cannot survive or flourish as closed communities. They are a part of a wider world, and need to engage and exchange with it to ensure their enduring economic and cultural vitality. In this way they can bend the mainstream and offer the real prospect of softening the endemic economic cycles of boom and bust. Only then can one really talk of sustainable economic development and neighbourhood renewal.

- Crucially, the process entails real and ongoing private, voluntary and public sector partnerships (which no doubt will, and should, acquire the PVP acronym) where all parties are prepared to change and create a whole which is greater than the sum of their parts. This implies the building on the ground of entirely new partnership structures which lead one towards the true meaning of community, which transcends dependence upon personalities, cultural identities, economic sectors and classes.

\section{Re-evaluating the community sector}

\section{THE PIVOTAL ROLE OF THE COMMUNITY SECTOR}

It has been the received wisdom for many years, even in the professional world of regeneration, that community initiatives are essentially oppositional movements that get in the way of the 'real' developers and official guardians of the public sector. At best they can be ignored, at worst they have to be paid off. Many community movements have internalised this view as well (it is sad to see how quickly they often melt away with such payoffs).

This is the great weakness of the current private/public sector partnership formula for regeneration, where the emergent community ('third' or 'voluntary') sector is frequently distrusted, devalued, and is rarely a major player if not completely excluded. But it is possible that society is arriving at a point where this is about to be turned on its head. Why is this? Apart from the manifest failure of many private/public sector partnerships to 


\section{Best practice example}

\section{Need for action research}

deliver real regeneration, in many circumstances community enterprises can now gather and mobilise, in a democratic context, social capital, knowledge and creativity. This, along with financial capital, material resources and little need for high returns to shareholders, is a recipe for success. Again and again, throughout the UK, it is beginning to emerge that many community-based options are intelligent, efficient and sustainable. They are both good at business and good at public service. But, if they are really to impact upon the future pattern of the mainstream, they will have to work with, and influence, the public and private sectors. One may also put this the other way round: the public and private sectors are coming to need the community sector. Historically the beginnings of this have been with housing associations, but the issue is now much wider and deeper than that.

A well-documented example of successful community enterprise is the North Kensington Amenity Trust (NKAT), which has over the last 30 years developed a large derelict site in Ladbroke Grove in partnership with the local authority, moving towards financial self-sufficiency (some 95 per cent of their income is now from commercial activity of some form or another). Currently it provides, in one of North Kensington's main thoroughfares, community and commercial space for well over 100 organisations and businesses, manages a large sports and leisure facility, runs a grants scheme, provides development advice and maintains ten acres $\left(40,470 \mathrm{~m}^{2}\right)$ of public space and helps with the Notting Hill Carnival. Its sustainable success has been a catalyst for the fortunes of the wider area.

Two big questions, which are likely to pursue the regeneration agenda for the next decade, stand out.

- How can one apply the examples of such community enterprise - born in the 1970s - to a radically different context of the inner city and its political economy in the first decade of the $21 \mathrm{st}$ century?

- How will private sector investment and energies be directly drawn into the strategic process of real regeneration, beyond increasing access to low-cost finance and charitable donations in cash or kind?

The current reviews of research on community-led regeneration published by the Department of Transport, Local Government and the Regions (DTLR) and the ODPM ${ }^{6}$ are inconclusive on these points. Many of the answers to these questions can only be found in practice during the implementation and evaluation of new projects like those of the Gillett Square partnership described above.

These questions can also be considered within a much wider context of ideas and observations. These concern the theoretical ideas of economic activity in this field and their application to 
Social and economic relationships underlie the visible surface of regeneration

\section{Need for mutual learning}

\section{Benefits of slower rates of return}

\section{Democracy essential}

contemporary opportunities and constraints. A few are presented below as part of an optimistic scenario, but there are many other relevant considerations that need to be brought to bear upon these matters.

- Regeneration is not just a matter of technology and money: beneath the visible surface of any successful development of the environment are its politics. This includes the particular relationships and activities that lead to the establishment of trust, common goals and principles.

- Business depends upon these social relationships; it is very rarely a matter of money alone, quick returns and high profits. The fact is that most economic exchange is pursued for social ends and one cannot indefinitely avoid naming and choosing what these ends are.

- With the world in a state of accelerating global crisis, the collective need mounts to make explicit, once again, these social definitions and choices in economic exchanges in the marketplace and in the conduct of public affairs.

- This will lead to a further articulation of common values, new partnerships and a major reconfiguration of the economy, and will increase opportunities to embark upon the making of a sustainable, cosmopolitan, democratic, fair and secular society.

These ideas may not be easy or immediately comprehensible to many in the private sector, and in that respect the community/voluntary/ third sector can set an example, as well as accepting that it too has much to learn. With mutual re-evaluation, the private sector can be helped to articulate and put into practice social aims and objectives common to all parties. This is not only a matter of espousing corporate social responsibility statements, or supporting some good cause or other, only to gain respectability and entry into new markets.

If the necessary new partnerships are to come about, the private sector may have to accept that a much slower rate of return is now the only sustainable way forward, that competition on its own is self-destructive and that it has to be tempered with cooperation. This is not just a moral imperative, but derives from a range of emerging global constraints on historic wastage of resources and destruction of the environment. It also derives from the recognition that the problem of increasing private wealth for some and public squalor for all (as described by J. K. Galbraith ${ }^{7}$ ) calls into question the current divisions of responsibilities between the private and public sector, the citizen and the state.

Above all, it is necessary to recognise that democracy (which includes issues of equality), driven in part by the internet, can open up wider opportunities for the application of social capital. This is an essential and welcome element for the regeneration of the economy, as well as for the cohesion of society, the health of the 
public domain and the growth of community. Such new and old prerequisites for sound business may be the mothers of invention, but also of the future itself.

\section{References}

1. Jacob, J. (1961) The Death and Life of Great American Cities, Vintage, London.

2. Office of the Deputy Prime Minister (2000) Our Towns and Cities, found at: http:// www.odpm.gov.uk/stellent/groups/odpm_control/documents/contentservertemplate/ odpm-index.hcst? $\mathrm{n}=2866 \& 1=2$.

3. Ball, M. (2002) 'Excuse me - but we have to live here', The Observer, 7 July; Galbraith, J. K. (1992) The Culture of Contentment, Houghton Miflin, Boston, MA; Hutton, W. (1996) The State We're In, Vintage, London; (2003) 'The pursuit of true happiness', The Observer, 9 March; Stiglitz, J. (2002) Globalization and Its Discontents, Penguin, London; Monbiot, G. (2001) Captive State: The Corporate Takeover of Britain, Pan, London.

4. (2002) The Observer, 16 June.

5. Florida, R. (2002) The Rise of the Creative Class, Basic Books, New York.

6. DTLR (2002) Neighbourhood Regeneration: Lessons and Evaluation Evidence from 10 SRB Case Studies, DTLR, available from: handr.research@dtlr.gov.uk; ODPM (2002) 'Community involvement: The roots of renaissance?', Urban Research Summary No. 5, ODPM, available from: h.r.summaries@odpm.gov.uk; ODPM (2003) A Review of the Evidence for Regeneration Policy and Practice, ODPM, available from h.r.summaries@odpm.gov.uk.

7. Galbraith, ref 3 above.

\section{(C) Adam Hart}

